\title{
Climate Changes and Its Consequences Case Study: Fog Occurrence in Isfahan City
}

\author{
Victoria Ezzatianand Zahra Jahanbani
}

\begin{abstract}
When the relative humidity reaches over than $\mathbf{9 5 \%}$ and the visibility under the 1000 meter fog has been occurred. In this paper we survey the fog phenomena frequency and the conditions of it in Isfahan city during 1992-2011. The calculations showed that in Isfahan city in Feb, mar, Jan\& Dec the fog phenomena more occurred. Significant synoptic pattern in foggy days shows that the dominant pattern is warm fronts. Usually in warm section (the area between warm and cold front) fog phenomena is seen. Receiving humidity from Persian gulf and Oman sea cause intensifying warm front , and cold air which penetrate from Siberian area to central part of Iran cause fog formation over Isfahan city.
\end{abstract}

Index Terms-Frontal fog, radiation fog, synoptic pattern, flight time.

\section{INTRODUCTION}

Whenever relative humidity of environment reaches up to more than $95 \%$ and the potential of visibility decreases below 1000 meters, fog phenomenon occurs [1]. Fogs play an important role in many environmental and ecological processes. The occurrence of fog is one of the most troublesome weather phenomena and present distinct hazards to city transport system in many areas. The limited visibility associated with fog is responsible for a loss of time and money in all forms of transportation [2], [3]. This phenomenon is seeing usually in all seasons and months of a year and hours of a day. Presence of water droplets in fog, causes sun light be scattered, and visibility decreases. In a fog layer the most condensed layer is the nearest layer to the ground, and the density will be decreased by increasing the altitude.

Some kinds of fog are as explained bellow [4]:

A-Radiation fog: usually occurs in clear nights and the main reason is that ground gets cold by shining long length waves of radiation (Fig. 1). Radiation Fog forms, when the ground cools rapidly after sunset by long-wave radiation to space. The cooling of the air near the ground makes it increasingly thermally stable, which weakens and eventually stops turbulence above ground. As radiative cooling continues, excess water vapor begins to condense into Fog droplets. As soon as the deepening Fog layer becomes optically thick (some tens of meters), the upper part of it becomes the effective interface to space.

Manuscript received August 31, 2013; revised November 1, 2013.

Victoria Ezzatian is with Research faculty of disaster management, Shaghespaghooh institute, Esfahan, Iran (e-mail: Victoria_ezzatian@yahoo.com).

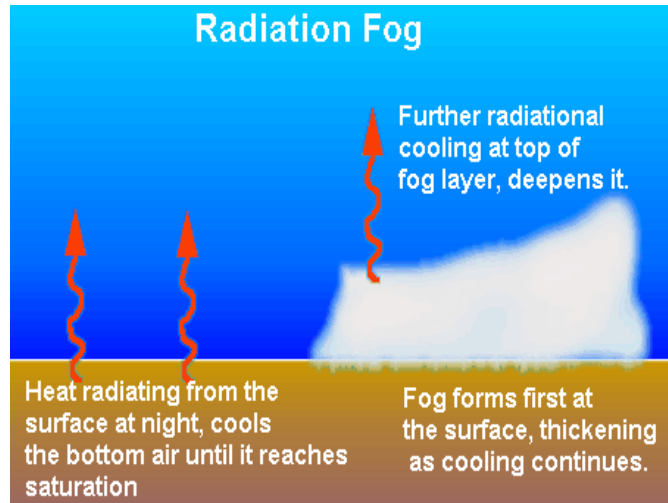

Fig. 1. Diagram showing the synoptic conditions for night-time radiation fog with front and side view panels. The typical vertical distribution of temperature, dew point temperature and wind are presented in the front panel.

B-Frontal fog: it happens because of confliction between a warm air mass and a cold one. This kind of fog usually happens on hills or sometimes in cold air in ahead of warm front.

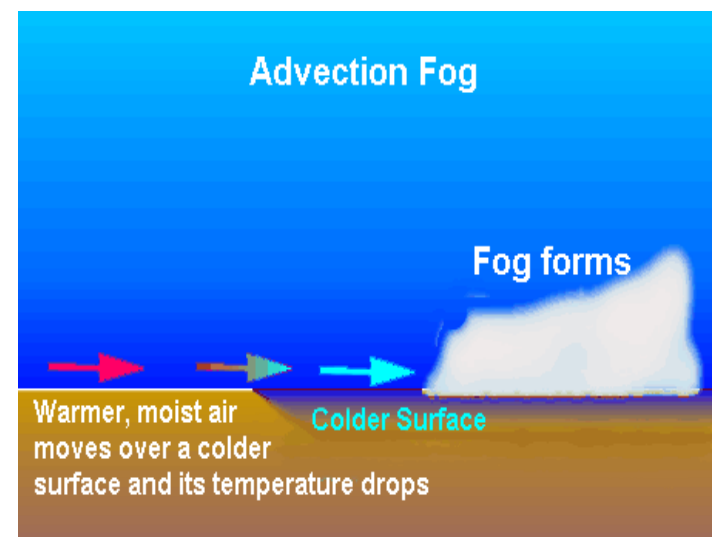

Fig. 2. Diagram showing the synoptic conditions for advection fog with fron and side view panels. The typical vertical distribution of temperature, dew point temperature and wind are presented in the front panel.

C-Convective fog: it is made when a warm air mass passes over a cold area of ground; valley fog and sea side fog are two samples (Fig. 2). When moist and warm air is advected by the wind, turbulent mixing in the boundary layer moistens the air from below. This results in advection stratus clouds. When Stratus encounters cooler waters (with sea surface temperatures lower than air dewpoint temperature) or cold (possibly snow-covered) land, turbulence and thermal convection decrease significantly, but the water vapor-driven convection from the surface continues to mix the overlying air. This leads to cooling of the unsaturated air and lowering of the cloud base, eventually even to the formation of Advection Fog [5]. The increased pollution levels may lead to the atmospheric reactions resulting into the formation of secondary pollutants that may also lead to increased 
pollutants in the atmosphere. The result showed that pollutants $\left(\mathrm{SO}_{2}, \mathrm{NO}_{x}, \mathrm{O}_{3}, \mathrm{CO}, \mathrm{PM}_{2.5}\right.$ and $\left.\mathrm{PM}_{10}\right)$ of fog are higher all days. These finding would be connected fog with pollutant [6], [7].

Important factors for the formation of Advection Fog are the fetch over the sea (or over land with wet snow) and wind speed [8]. A long fetch together with not too high a wind speed allows the cloud to sink lower and eventually form Fog [9], [10]. Over land areas the snow temperature is an important factor: snow having below-zero temperatures can easily absorb moisture from overlying air [11]. This is due to the smaller water vapor pressure for ice surfaces compared to liquid water surfaces [12], [13]. Fog formation over dry snow is; therefore, much more common than over wet snow, as wet snow is a source of moisture for Ardabil airport, between all of fogs, 41 percent were Radiation type, 31 percent were frontal type and 28 percent were advection type. Examination of fog synoptic patterns indicated that 4 effective synoptic patterns have role in formation of fog that mainly in earth surface is consist of influence of Siberia high pressure that spreads from Northwest to northeast of Khazar sea, formed high pressure that spread upon Eastern Europe and high pressure upon Khazar sea and at up of atmosphere, generally is consist of ascent and descent flows in 500 hectopascal geopotential heights.

\section{Methodology}

In this paper statistical and synoptic analysis of 20 years are used (1992-2011) including average temperature, dew point, relative humidity, wind speed, amount of clouds, and fluctuation of air pressure in 24 hours in foggy days.

\section{RESEARCH DOMAIN}

The studied area is located in north east of Esfahan city; geographical properties are as explained below: $44^{\prime}$ North \& $51^{\circ} 51^{\prime}$ East.

\section{FOG AND HORIZONTAL VISIBILITY}

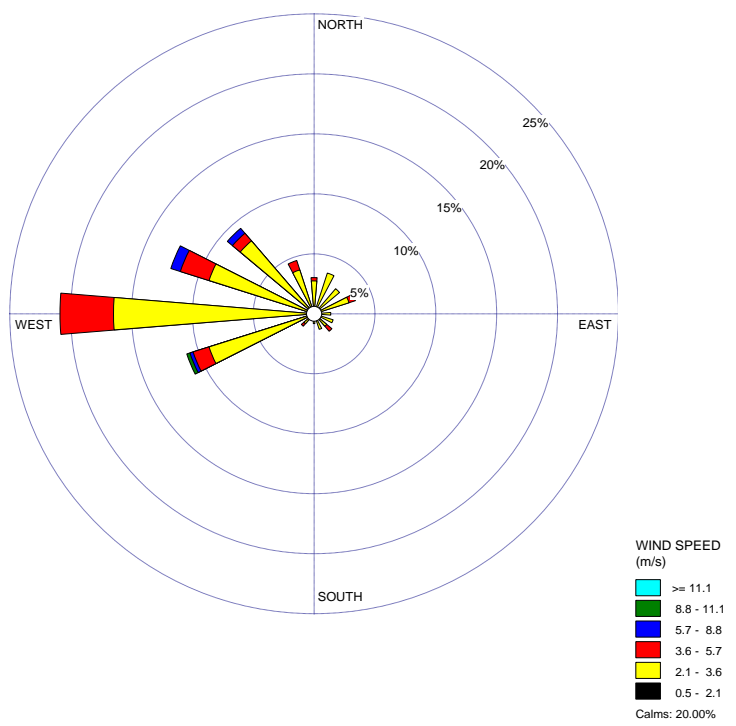

Fig. 3. Annual wind rose 03 UTC.
Other factors affecting horizontal visibility are the direction and velocity of wind because wind can transport humidity [14], [15]. Analyzing long range wind data in Isfahan Airport meteorological station shows that the dominant wind of this land is the wind which blows in direction South West \&West, but hourly scale shows that wind direction from west direction in the morning and late at night changes gradually to east in the afternoon (Fig. 3, Fig. $4)$. Note that the airport meteorological station is located on the boundary of Isfahan city and the desert of "SEGZI DESERT". So the environment, experiences two different climates, while late at night cold air of desert penetrates this area and decreases temperature. So the air condenses, and the humidity reaches the saturation level. The existing dust and pollutants in the air prepare condensing nucleons for attracting humidity, finally causing fog and decrease visibility. The presence of salt, sand, and chalk mines in "SEGZI DESERT" and remains of "Gavkhooni lagoon" causes existence of many suspended particles in the air (Fig. 5, Fig. 6).

Wind rose shows that the quantity of winds from west direction is the most. The north west and south west.

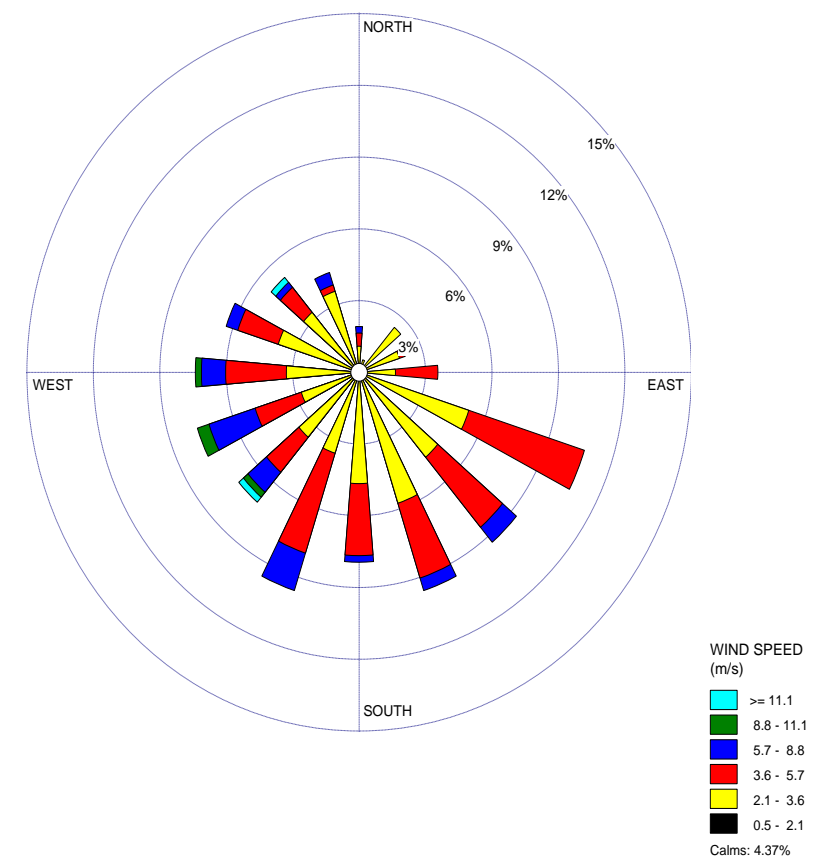

Fig. 4. Annual wind rose 06 UTC.

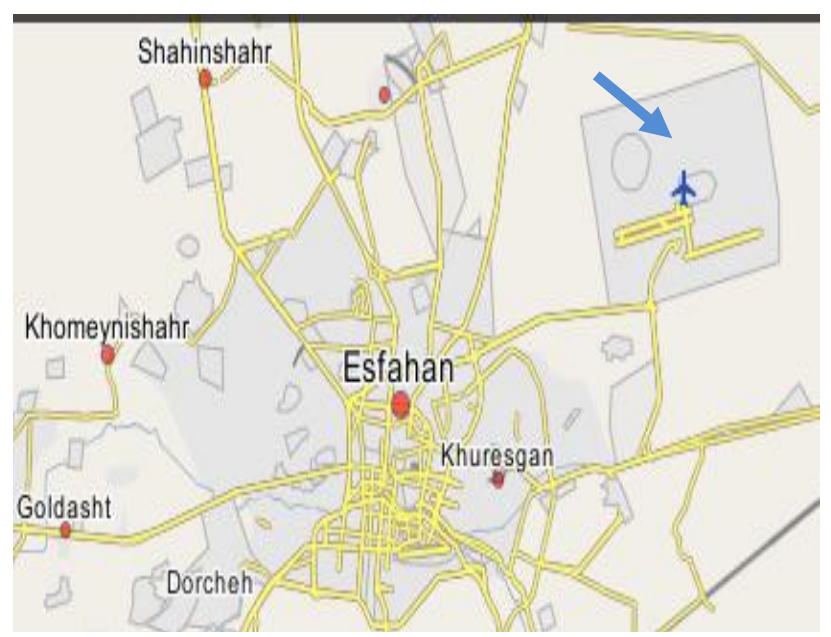

Fig. 5. The location of Isfahan airport captured from Google Map. 
Wind rose shows that in 06 UTC south east and eastern winds intensify, so weakens the conditions of fog formation.

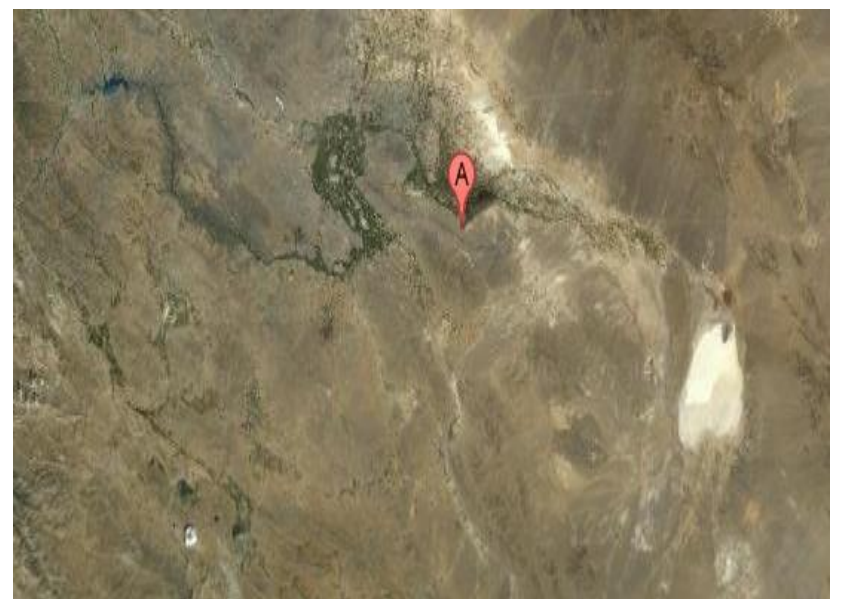

Fig. 6. Isfahan city and Gavkhooni lagoon capture by NASA satellites.

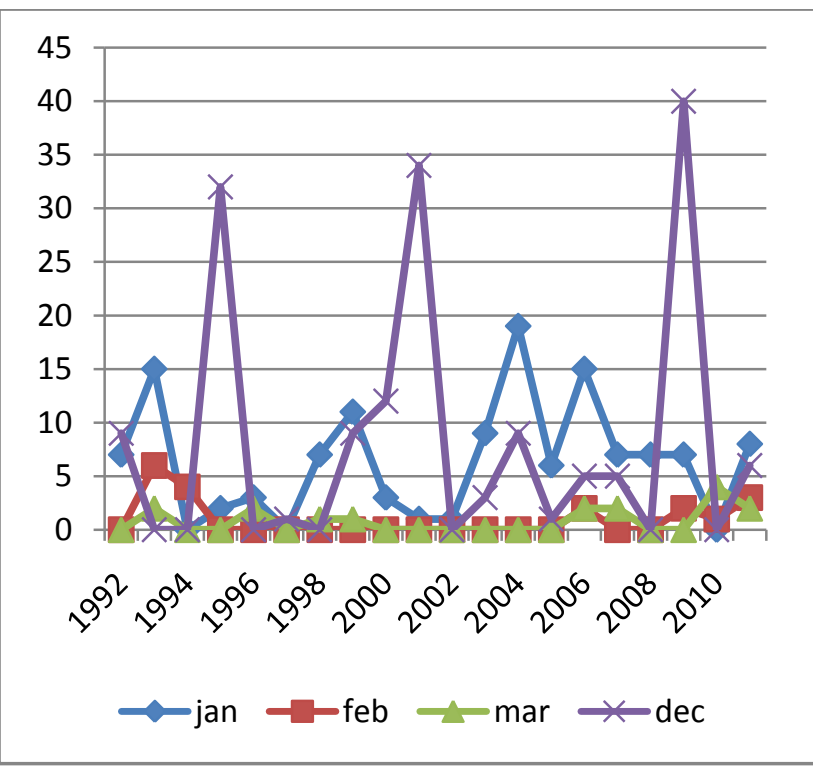

Fig. 7. The number of fog occurrence in Dec., Jan., Feb., Mar. The vertical axe is frequency and the horizontal axe is year.

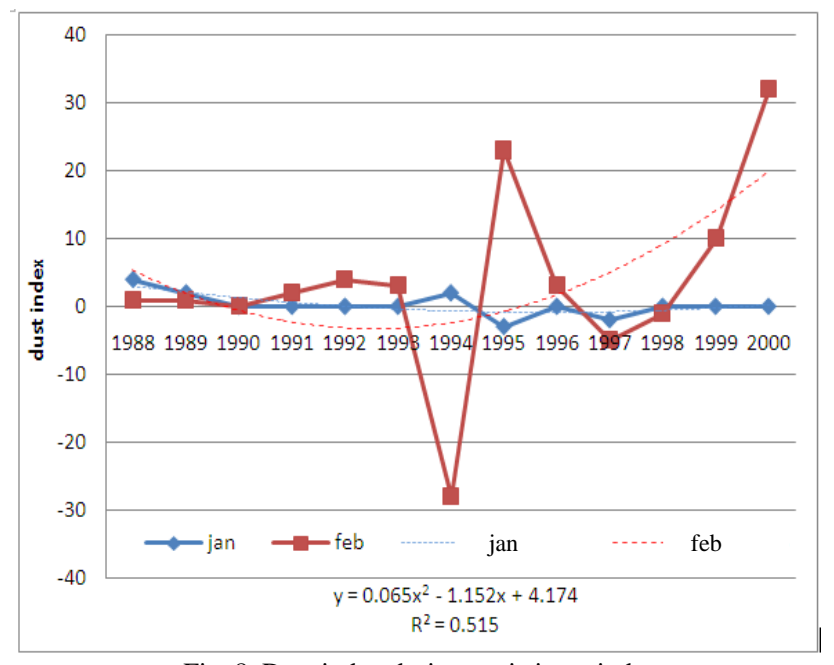

Fig. 8. Dust index during statistic period.

Fig. 7 shows that in December fog phenomenon occurs more than other months. And also shows the fluctuation is the least in March.

The graph shows that in February dust index fluctuates much more than in January.

\section{Flight Time}

TABLE I: THE NUMBER OF FOGGY DAYS IN THE PERIOD

\begin{tabular}{|c|c|c|c|c|}
\hline year & Jan & Feb & Mar & Apr \\
\hline 1992 & 7 & 0 & 0 & 9 \\
\hline 1993 & 15 & 6 & 2 & 0 \\
\hline 1994 & 0 & 4 & 0 & 0 \\
\hline 1995 & 2 & 0 & 0 & 32 \\
\hline 1996 & 3 & 0 & 2 & 0 \\
\hline 1997 & 0 & 0 & 0 & 1 \\
\hline 1998 & 7 & 0 & 1 & 0 \\
\hline 1999 & 11 & 0 & 1 & 9 \\
\hline 2000 & 3 & 0 & 0 & 12 \\
\hline 2001 & 1 & 0 & 0 & 34 \\
\hline 2002 & 1 & 0 & 0 & 0 \\
\hline 2003 & 9 & 0 & 0 & 3 \\
\hline 2004 & 19 & 0 & 0 & 9 \\
\hline 2005 & 6 & 0 & 0 & 1 \\
\hline 2006 & 15 & 2 & 2 & 5 \\
\hline 2007 & 7 & 0 & 2 & 5 \\
\hline 2008 & 7 & 0 & 0 & 0 \\
\hline 2009 & 7 & 2 & 0 & 40 \\
\hline 2010 & 0 & 1 & 4 & 0 \\
\hline 2011 & 8 & 3 & 2 & 6 \\
\hline & & & & \\
\hline
\end{tabular}

TABLE II: THE STARTING TIME OF FOG STARTING IN A DAY

\begin{tabular}{|c|c|c|c|c|c|c|c|c|}
\hline fog & 00 & 03 & 06 & 09 & 12 & 15 & 18 & 21 \\
\hline frequency & 64 & 110 & 81 & 13 & 4 & 5 & 18 & 33 \\
\hline
\end{tabular}

Fog is the main phenomenon affecting visibility which causes so many problems for landing and boarding of air planes [16], [17]. This phenomenon is most seen in Jan., Feb., Mar., and Dec., (Fig. 7), (See Table I) especially at 03UTC, simultaneously with sunrise. And after the sun rises, gradually the fog density will be decreased, and usually at 07UTC to 21UTC there is suitable visibility in the area (See Table II). In Fig. 8 we see that in Feb. dust index fluctuates much more than in Jan.

The difference in levels of precursor emissions accounted for the majority of the difference in the contributions by different source regions to $\mathrm{O}_{3}$ formation. In addition, meteorological conditions also played important roles in the formation and distribution of $\mathrm{O}_{3}$. The clear and hot weather as well as light winds favored the photochemical production and accumulation of $\mathrm{O}_{3}$ in and around Esfahan (Fig. 9. A, B).

Fig. 9 show that in fogy days in surface tropical high pressure dominants south area of Iran (over Red Sea), therefore humidity will be transferred into Iran and prepares the situation for fog formation.

Fig. 9A dedicates to surface and Fig. 9B dedicates to weather patterns in 500 hectopascal.

$$
\text { Visibility }=-0.035 \text { cloudiness }-14.864
$$

In Eq. (1) we see that visibility have inverse relationship with cloudiness, if the amount of clouds increases the 
visibility decreases. Significant differences among months were observed in concentrations of $\mathrm{SO}_{2}, \mathrm{NO}_{\mathrm{X}}, \mathrm{NO}, \mathrm{NO}_{2}, \mathrm{O}_{3}$, $\mathrm{CO}, \mathrm{PM}_{2.5}$ and $\mathrm{PM}_{10}$ in different between the days. In fog days, the values of $\mathrm{SO}_{2}, \mathrm{NO}_{\mathrm{X}}, \mathrm{NO}, \mathrm{NO}_{2}, \mathrm{O}_{3}, \mathrm{CO}, \mathrm{PM}_{2.5}$ and $\mathrm{PM}_{10}$ are higher $21.0 \%, 90.5 \%, 256.0 \%, 38.9 \%, 67.3 \%$, $84.0 \%, 67.3 \%$ and $74.7 \%$ of high all days, respectively. On foggy days atmospheric pollution is rather serious, and the high values of pollutants occur when fog forms.
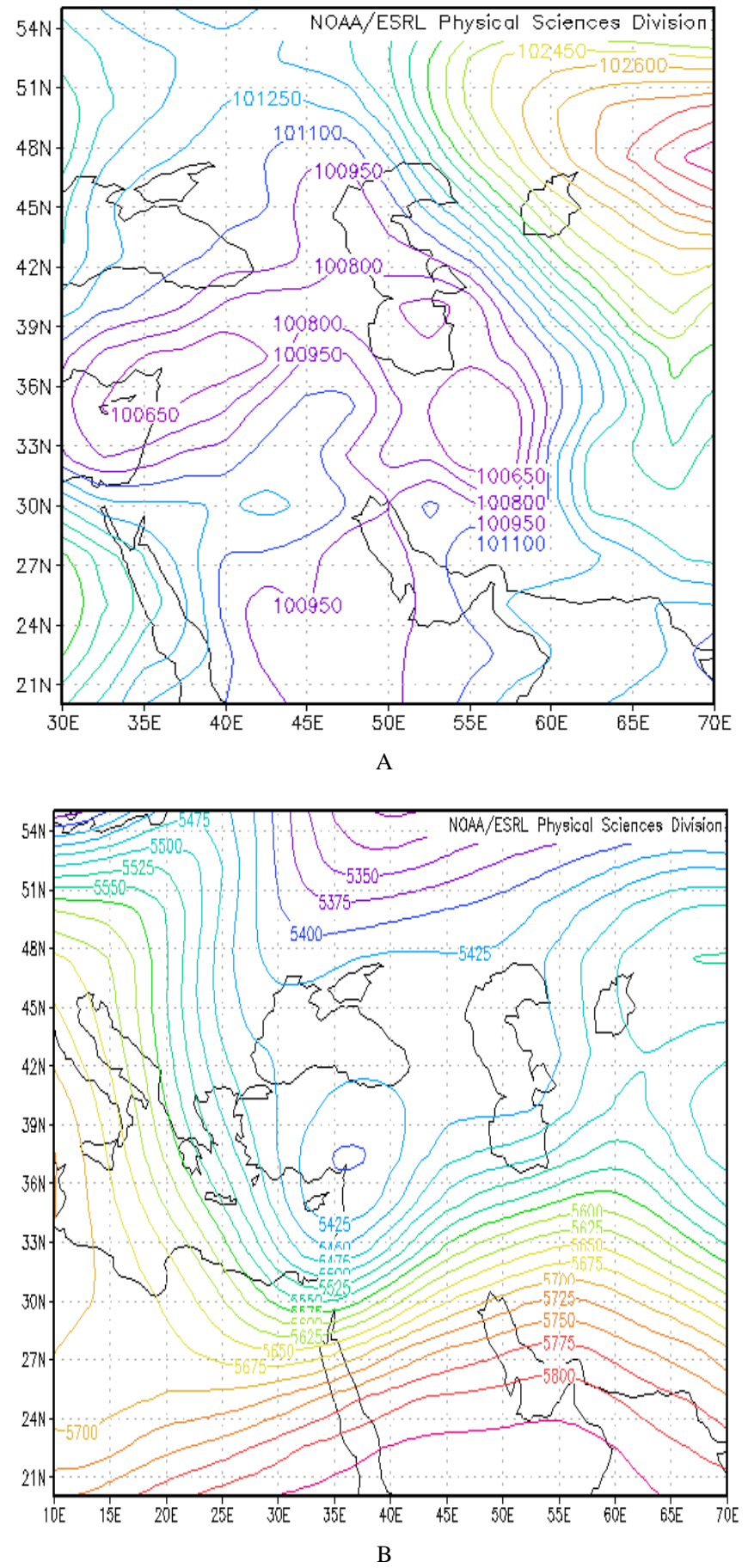

Fig. 9. Weather map in surface and 500 hectopascal level 12 UTC 08/01/1993.

\section{RESUlTS}

Analyzing the data of Esfahan airport meteorological station during 20 years (1992-2011) shows that:

- During 20 years in 407 cases, visibility was reported less than $1 \mathrm{KM}$. The most frequency of fog was reported in the years $2009 \& 2011$, and the least frequency are dedicated to the years $1997, \& 2002$

- 128 cases of fog out of 328 have occurred in Jan, 18 cases in Feb, 16 cases in Mar., and 106 cases in Dec.

- Analyzing starting time of fog shows that the most cases start in 03UTC (110 cases), and 06UTC (18 cases), and the least cases start in 12UTC (4 cases). So there are the best time for a flight operation in Jan., Feb., Mar and Dec. Is from 09UTC to 18UTC.

- The Pierson correlation efficiency and multi variation regression equations show that the most important factor affecting visibility and fog are relative humidity and cloudiness.

- In winter time synoptic weather patterns shows temperature inversion and warm front case making radiation or frontal fog. Radiation fogs occur some hours or one day after rain, because raining prepare necessary humidity for fog forming and the temperature decreasing cooperate with fog to be continued.

\section{CONCLUSION}

Radiation fogs are sometimes formed because of inversion. Microclimatological properties of area and existence of high pressure systems in ground level and high altitude contour in 500 hectopascal level, cause intensifying stability and cooperate with fog to be formed. Ahead of warm front due to combination of two air masses and increasing existence humidity frontal fog is formed. The humidity has come from "Oman Sea and Persian gulf". And the cold air has come from "Siberian area".

\section{REFERENCES}

[1] S. N. Stolaki, S. A. Kazadzis, D. V. Foris, and S. Karacostas, "Fog characteristics at the airport of Thessaloniki, Greece Agricultura Insurance Organization, Greece," Nat. Hazards Earth Syst. Sci., vol. 9 , pp. 1541-1549, 2009.

[2] P. K. Quinn and T. S. Bates, "Regional aerosol properties, aerosol IS99, index, ACE Asia, TARFOX, \& NEAQS," J. Geophys. Res., vol. 110, no. d14, pp. 202, 2004.

[3] Y. Zhang, X. L. Zhu, S. Slanina, M. Shao, L. Zeng, M. Hu, M. Bergin and L. Salmon, "Aerosol pollution in some Chinese cities," Pure Appl. Chem., vol. 76, no. 6, pp. 1227-1239, 2004

[4] X. S. Wang, J. L. Li, Y. H. Zhang, S. D. Xie, and X. Y. Tang, "Ozone source attribution during a severe photochemical smog episode in Beijing, China," Science in China Series B: Chemistry, vol. 52, issue 8 , pp. 1270-1280, August 2009.

[5] B. Salahi and S. Mohammadi, "Synoptic and statistical analysis of fogs in Ardabil airport and presentation of suitable flight hours," Physical Geography Quarterly, no. 77, pp. 69-92, Fall 2011.

[6] H. E. Landsberg, "The urban climate," Academic Pr, College of Environmental Sciences and Engineering, Peking University, Beijing 100871, China, 1981.

[7] M. Witiw and S. La Dochy, "Trends in fog frequencies in the Los Angeles Basin," Atmospheric Research, vol. 87, pp. 293-300, 2008.

[8] M. Mohan and S. Payra, "Influence of aerosol spectrum and air pollutants on fog formation in urban environment of megacity Delhi, India," Environmental Monitoring and Assessment, vol. 151, pp. 265-277, 2009.

[9] J. H. Seinfeld and S. N. Pandis, Atmospheric Chemistry and Physics From Air Pollution to Climate Change, 2nd Ed. John Wiley \& Sons, 2006.

[10] Y. Wang, J. Guo, T. Wang, A. Ding, J. Gao, Y. Zhou, J. L. Collett Jr. and W. Wang, "Influence of regional pollution and sandstorms on the chemical composition of cloud/fog at the summit of Mt. Taishan in northern China," Atmospheric Research, vol. 99, pp. 434-442, 2011.

[11] K. Chen, Y. Yin, and Z. H. Hu, "Influence of air pollutants on fog formation in urban environment of Nanjing, China," Procedia Engineering, vol. 24, pp. 654-657, 2011. 
[12] M. Witiw and S. L. Dochy, "Trends in fog frequencies in the Los Angeles Basin," Atmospheric Research, vol. 87, pp. 293-300, 2008.

[13] H. E. Landsberg, The Urban Climate, Academic Pr, 1981.

[14] M. Mohan and S. Payra, "Influence of aerosol spectrum and air pollutants on fog formation in urban environment of megacity, Delhi, India," Environmental Monitoring and Assessment, vol. 151, pp. 265-277, 2009.

[15] J. H. Seinfeld and S. N. Pandis, Atmospheric Chemistry and Physics From Air Pollution to Climate Change, 2nd Ed. John Wiley \& Sons, 2006, pp. 434-442.

[16] M. R. Witiw and S. La Dochy, "Trends in fog frequencies in the Los Angeles Basin," Atmospheric Research, vol. 87, pp. 293-300, 2008.

[17] R. S. Schemenauer, C. M. Banic, and N. Urquizo, "High elevation fog and precipitation chemistry in southern Quebec," Canada.

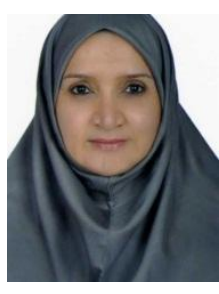

Victoria Ezzatian was born in Iran in 1964. She got B. Sc Physics, M. Sc climatology, Ph.D. climatology in Meteorology, Regional Meteorological Training Center, Esfahan University, Iran. since 1986, she was a weather forecaster, the chief of forecasting center in meteorological organization, the chief of Applied Meteorological Research center, head of Air Chemistry, Ozone, \& Air Pollution Research center, head of physical meteorology research Group, manager of tourism Group of Naghshe Jahan University.

She Teaches different courses in university such as: physics, statistic, meteorology, climatology, remote sensing, ecotourism, air pollution, geophysics, geography, etc. for more than 20 years. Cooperating with establishing seminars and conferences, preparing 70 articles about air pollution, air quality, spectroscopy with Brewer \& Dobson, ozone \& UV, natural disaster and hazardous phenomena, for internal seminars and a paper forstatistical climatology international conference (2007-China)

She is a member of ASPEC, biological \& environmental engineering society- expert of intergovernmental panel for climate change - member of Esfahan environmental advisory group. 